\title{
Reading through Galileo's Telescope: Margaret Cavendish and the Experience of Reading*
}

\author{
by Elizabeth A. Spiller
}

This essay reassesses the role of reading in the context of seventeenth-century natural philosophy by analyzing Galileo Galileis Starry Messenger and Margaret Cavendish's The Blazing World. The unreliability of telescopic vision becomes a dominant metaphor for the unreliability of reading printed texts. Where Galileo sought to put the reader in his own position as a scientific observer by making reading a form of observation, Cavendish used the telescopic image to show how readers become the makers of their own fictions. From the recognition that reading and observation finally reveal our relationship to the world rather than the world itself comes what will ultimately be the modern assumption that acts of observation are also acts of reading.

I n April of 1611, Galileo demonstrated his new telescope to prominent observers at a villa outside Rome. When the telescope was pointed at the heavens many present were not convinced that what they saw were satellites around Jupiter or mountains on the moon. Observers were impressed, however, by Galileo's ability to use his optic tube to read inscriptions carved on a distant building. Julius Caesar Lagalla disputed the ability of the telescope accurately to show objects on the moon; he nonetheless enthused that the telescope made it possible to "read the letters on the gallery which Sixtus erected in the Lateran ... so clearly, that we distinguished even the periods carved between the letters, at a distance of at least two miles." In demonstrating the telescope on the Lateran palace, Galileo's intention was to show observers that this new technology offered reliable representations of distant objects. Lagalla's unwillingness to believe Galileo's claims about the lunar observations - like the famous refusals of Guilio Libri and others even to look

*I would like to thank Douglas Bruster, Barbara K. Lewalski, Jeffrey Masten, and the reviewers from Renaissance Quarterly for commenting on earlier drafts of this essay. Peter Lynch and John Norman generously shared their expertise on several key points.

${ }^{1}$ Lagalla, 8. Lagalla's response anticipates later theological reaction against Galileo. When Pope Sixtus V (1585-1590) took office, he began renovating Rome as a visible symbol of the counter-Reformation papacy. The text that Lagalla read through Galileo's telescope was a recent inscription that adapted classical architecture for the new church. Designed to figure the church as a successor to imperial Rome, inscriptions like those on the Lateran palace "wrote out" a church policy that eventually became incompatible with Galileo's work in astronomy. For descriptions of Galileo's trip to Rome as marking "the end of the arguments" about the validity of the telescope, see Van Helden, 1989, 113, 109-113. See also Rosen, 3066; Drake, 1978, 166-67; on Sixtus's work, see Petruci, 36-38. 
through the telescope - are many and complex. ${ }^{2}$ This incident certainly reveals new concerns about both the status of observational evidence and the reasons that observations were particularly problematic in astronomy. While allowing others to see the moon more closely, Galileo's visual demonstration could not actually carry them there. Here, however, what interests me is not so much Lagalla's unwillingness to believe what he saw of the moon as his excitement over what he saw on the Lateran. When he reads Sixtus's new inscriptions from that hilltop outside Rome, Lagalla is not using the telescope as an observational tool; instead, he is using it as a reading device.

If the difficulty that Galileo's witnesses face is, for them, one of seeing, we might argue that it is also one of reading. When Lagalla reads through Galileo's telescope he reacts indirectly to Galileo's attempt in The Starry Messenger (1610) to persuade readers of the new discoveries he has made with the telescope by getting them to adopt a new way of reading. While Lagalla makes himself a reader rather than an observer, Galileo wants to make his readers into observers. More generally, Lagalla's intuitive acceptance of the telescope as an appropriate tool for reading points to a larger affiliation between reading and the telescope. During the early modern period, telescopes and reading shared a close alliance. In a tradition originally derived from Roger Bacon's claims about the powers of catoptric glasses, early modern philosophers such as Thomas Digges repeatedly tell stories about the telescope's power as tool for reading distant texts. The lesson of these stories is that the telescope enhances - magnifies, as it were - a natural but limited human ability to read. ${ }^{3}$ Reading is often associated with the telescope be-

${ }^{2}$ See Blumenberg, 657-74; Van Helden, 1994, 9-16.

${ }^{3}$ Reading texts through telescopes was more common than we would expect because it became the accepted way to determine the magnification power of an instrument. When $\mathrm{Pa}$ olo Sarpi was first asked to test an instrument for the Senators of Rome, he did so by determining how much it enlarged a line of text. On the development of this practice, see Van Helden, 1994, 25-28. The origin of most stories about reading texts through optic glasses, however, seems to be more mystical and to come out of Roger Bacon's claim to be able to read distant texts with his glasses. Most of these stories - repeated by writers such as Agrippa, Thomas Digges, John Wilkins, and Thomas Birch - attribute a mystical power to the telescope as a secret reading device. Wilkins literalizes this claim when he says that Pythagoras wrote directly on the lens of a catoptric glass which he then used to project the letters he wrote onto "the circle of the Moone, where they should be legible" from miles away. Where an ordinary telescope creates an image - a representation - for the viewer to see, Pythagoras's mythic catoptric glass reverses this process. Written onto the surface of the glass, the representation is here only a projection of what is literally inherent in the glass. That is, it is not simply that the glass distorts the representation: as many feared and perhaps others hoped, the representation produced by the glass distorts reality as it changes what a (nakedeye) viewer sees of the moon itself. Wilkins, 96; see also Gunther, 1:268; Agrippa, 1, 16-17; Digges, fol. A4r; Birch, 3:16-18. 
cause both were understood as powerful, but potentially dangerous, ways of acquiring knowledge. As the recurrence of such stories suggests, what reading did was surprisingly analogous to what the telescope did: both were tools that worked across distance and made it possible to see things that were otherwise inaccessible. Yet, in doing so, these were "technologies" in which the means to new knowledge involved distorted and potentially dangerous forms of mediation.

To a twentieth-century perspective, connecting reading to the cognitive and philosophical problems associated with the telescope may seem arbitrary. Yet, this claim should not be understood as simply an analogy that reflects current literary-historical interest in the topic of reading. Indeed, the philosophical problems that early modern thinkers faced with both reading and the telescope are hard for us to recognize precisely because we are accustomed to accepting both the immense power and inherent limitations to knowledge that are in some way indirect, mediated, or vicarious. We unthinkingly rely on and yet also mistrust such information technologies. In the seventeenth century, by contrast, the relationship between reading and information - factual and fictive - is changing. On the one hand, reading is increasingly becoming a form of education and entertainment as works of imaginative fiction give readers vicarious experiences that "nothing affirms." At the same time, however, reading is also presented as a new source of information: manuals, guides, and travel narratives offer knowledge that could not, for most readers, be gained through personal experience or authority. ${ }^{5}$ In both cases, reading lacks the authority of direct experience: the possibilities of new print media are also its dangers.

After Copernicus, new work in astronomy seemed not so much to reveal new truths as it did create new doubts of old certainties. As John Donne concludes, this is an age in which knowledge can no longer produce certainty for the "new Philosophy cals all in doubt" (1994, 255). In this historical context, the telescope became an image of doubtful knowledge because it was an instrument in which distortion became the means to truth. The telescope thus became a perfect figure for reading because it, like reading, was understood as a technology of mediated knowledge. Michael Baxandall has suggested that every culture has its own "period eye": the physical act of seeing is culturally conditioned in ways that determine cognitive perception. The way one sees determines what one can know. As an instrument whose reputation for unreliability was only later transformed into a standard that made it an enduring metaphor for knowledge, the tele-

${ }^{4}$ Sidney, 57.

${ }^{5}$ Shapiro, 260. 
scope clearly shaped the "period eye" of the early modern age. ${ }^{6}$ Whether in Jan Vermeer's paintings or in John Milton's poetics, this period is characterized by a new attention to the visual texture of the world as observers learn to see with a precision that made things both more minute and greatly magnified. ${ }^{7}$ This visual texturing of the world is a product not simply of the telescope but of what the telescope suggests about how we see at all. What Svetlana Alpers argues of Johannes Kepler is true more generally: it is not the recognition that visual phenomena may be distorted and misleading that is new in this period. Rather, the telescope and other new optic devices reveal how distortion is the basis for all acts of perception (35). In the new visual culture of the seventeenth century, the telescope thus exemplifies the powers and limits of reading as a form of apprehension.

This essay historicizes the problems that readers faced in this new visual culture by examining Galileo's Starry Messenger and Margaret Cavendish's Description of a New World, called the Blazing World (1666). Making their texts work like telescopes, Galileo and Cavendish adapt the visual technology of the telescope into a model of reading. In Galileo's case, both the evidence produced by and the form of the telescope generate the structure of the book. In this work of visual astronomy, Galileo wants to show his readers new discoveries that he saw through the telescope. In substance, The Starry Messenger seems to be a model of the observational methodology that comes to be associated with empiricism: what Galileo documents is strictly personal experience. Yet, where philosophers such as Francis Bacon insist that texts should be verifiable, Galileo writes his text with the recognition that his claims would not immediately be verifiable. Integrating the visual distortion of the telescope into the text, Galileo makes The Starry Messenger into a visual instrument for seeing what he has seen. Thus, reading becomes not an impetus to further verification, but a form of textual observation that becomes an alternative to verification.

Cavendish extends Galileo's understanding of reading as a form of observational experience. Cavendish's situation, in England in the 1660s, differs in important ways from Galileo's position in Italy earlier in the century. Yet, by the end of the seventeenth century, Galileo had become so closely associated with the telescope that, for many English writers, he became a figure for the kind of knowledge produced by the telescope. Marjorie

\footnotetext{
${ }^{6}$ Baxandall, 29-108. On how sight - and the telescope in particular - functions as a dominant trope for knowledge, see Rorty, 11-13, 38-51 and Reiss, 1982, 31-33, 54. For the argument that the telescope exemplifies the transition from a traditional understanding that reality is what you see to a modern definition of reality as that which is invisible, see Blumenberg, 617-74.
}

${ }^{7}$ On Vermeer, see Alpers, 26-33; on Milton, see Nicolson, 1935, 1-32. 
Nicolson identifies The Starry Messenger in particular as "the most important single publication ... of the seventeenth century, so far as its effect upon the imagination is concerned" $(1956,4)$. Yet, the impact that Galileo had on the cultural imagination was complex. As Amy Boesky suggests, Milton saw Galileo as a representative of both the intellectual power and danger associated with the telescope's augmented vision (30). Like Lagalla, Margaret Cavendish was dissatisfied with what she saw when she used the telescope. Although Robert Hooke's recent work with microscopes provides the main impetus for The Blazing World, it is thus Galileo who appears as the representative of observational optics in Cavendish's catalogue in The Blazing World of "the most famous modern Writers." ${ }^{8}$ Thus, Cavendish's advocacy of reading as a form of "true" experience arises out of a resistance to the technology represented by the telescope that is the ultimate consequence of Galileo's adherence to such technology. Their different conclusions about the telescope produce a similar understanding of the problems and importance of reading as a means to knowledge. Without Galileo, one might say, Cavendish would not exist. In The Blazing World, Cavendish uses the utopian romance - a genre whose central concern is that which could be but is not true - to comment on the inadequacies of experimental and observational science. Cavendish challenges the way that this understanding of natural philosophy impoverishes readers by its narrow definition of personal experience. Using a frame narrative that replicates the structure of telescopic vision, Cavendish defines the boundaries of her fictional world with the telescope. As in The Starry Messenger, what Cavendish's text represents cannot be verified because it cannot be seen by the naked eye. Agreeing with Galileo's assumption that reading itself can give us "experience," Cavendish rejects the notion of verification itself. Iterability - an increasingly important scientific practice requiring that experiences be repeated so that results can be verified - is unintelligible in the context of Cavendish's belief in singularity. Reading, for Cavendish, is an experience, but it can only be verified by producing one's own world through one's own imagination.

In part because the admittedly idiosyncratic "experiences" of these works could not be duplicated, both Galileo's Starry Messenger and Cavendish's Blazing World have been regarded as largely eccentric failures. In this context, Galileo and Cavendish's works have been interesting as examples of provocative but not fully successful attempts to create a self. As critics have noted, both writers responded to their isolation - for reasons of class, citizenship, politics, or gender - from larger intellectual communities by using the language of absolutism to articulate alternative selves. Thus, as Mario Bi-

${ }^{8}$ Cavendish, 1666, 89. Citations included in the text are from this edition. 
agioli suggests, Galileo departs from available models of scientific writing in The Starry Messenger: by using the language of the Medici court, Galileo simultaneously legitimates the "natural" absolutism of the Medicis while also making himself a new kind of scientific ambassador to their power. ${ }^{9}$ Initially isolated by politics from her homeland and by gender from full participation in the international intellectual community, Margaret Cavendish likewise uses the language of political absolutism to define a new kind of poetic practice. In Catherine Gallagher's terms, "what at first appears to be an absolutism that would merely lead to the subjection of all individuals except the monarch was actually for Cavendish the foundation for a subjectivity that would make its own absolute claims." ${ }^{10}$ These readings, while insightful, are primarily concerned with understanding Galileo and Cavendish as writers who have failed, albeit interestingly, in their authorial intentions. In this essay I argue that their texts are perhaps less about authors than about readers. Once we consider the reader, these rexts no longer come across as eccentric, if compelling, failures. Just as the category of authorship evolves in this period, so does the act of readership. If authorship changes because of new understandings of subjectivity, it may be fair to say that readership is transformed under new understandings of objectivity. In The Starry Messenger and The Blazing World we will see how readers are transformed from the author's passive objects to become active subjects apprehending objects through their reading as a result of disciplinary assumptions being made about the relationship between the text and the "world" it seeks to represent.

Galileo's Starry Messenger, the first published work on the telescope, exemplifies the problems involved in attempts to reproduce a visual experience in textual form. ${ }^{11}$ As the reception history for The Starry Messenger suggests,

${ }^{9}$ Biagioli, 1990, 233, 244-45. On Galileo's use of political arguments to compensate for his isolation from the highest intellectual standing in the universities, see also Biagioli, 1993, 18, 151-56, 227-32 and Winkler and Van Helden, 1992, 198-99.

${ }^{10}$ Gallagher, 27. Sherman, 184-6, uses rhetorical theory to argue that while Cavendish does try to construct an "autonomous self," her understanding of authorship as dependent on history undermines that project. Keller, 457, 462-3, examines Cavendish's philosophy to conclude that her critique of mechanism also involved a critique of mechanism's assumption of a discrete and absolute self. Yet, even as recent criticism has complicated Gallagher's identification of subjectivity in Cavendish, discussions of Cavendish's work continue to give primary attention to the topic of authorial subjectivity. I would like to change the terms of this ongoing debate by thinking about Cavendish not so much as an author, but as a reader who became an author and who thus has much to say about her and our positions as readers.

${ }^{11}$ Galileo, 1610. Citations included in the text are from Van Helden, 1989. 
book and telescope became metaphors for one another. Everyone who read The Starry Messenger — or even heard about Galileo's discoveries — seemed to want a telescope. ${ }^{12}$ Instead of presenting his patron with simply a copy of his book, Galileo also sent Cosimo de' Medici a telescope. ${ }^{13}$ When Galileo had official presentation copies of his book sent to courts in Prague, Rome, and England, he also included telescopes. When the first copies of Galileo's book arrived in Venice, the English ambassador Sir Henry Wotton was able to send a copy back to England with the promise of a telescope "by the next ship"; one of Thomas Hariot's correspondents immediately wrote to request "all sortes of thes Cylinders" and "also one of Galileus bookes if anie yet be come over and you can get them." 14 Less privileged readers made the same literalized association of book and relescope. When one of Galileo's friends in Florence received a package from him just after the publication of The Starry Messenger, neighbors assumed it was a telescope: "I could not defend myself against the people who wanted to know what it was, thinking that it was a telescope." When it turned out that the package contained a copy of the book, they nonetheless insisted that he read it aloud to them that night. ${ }^{15}$ As this anecdote suggests, text and instrument are logical complements to one another - had the package contained a telescope, the story would not have ended differently.

Galileo makes two important claims in The Starry Messenger: first, that the moon's surface is rough and mountainous; second, that there are four satellites orbiting Jupiter. In responding to this work, historians have been most concerned with the excitement and resistance generated by the intellectually radical nature of Galileo's claims. Galileo's assertion that there were mountains on the moon directly challenged assumptions that the celestial realms were perfect and unchanging while the discovery that satellites orbited Jupiter showed that the earth was not unique in having a satellite, weakening one argument for a heliocentric universe. ${ }^{16}$ Without disputing the value of these points, I want to redirect attention to the problems that Galileo faced in writing The Starry Messenger. ${ }^{17}$ On one level, Galileo understands his work as a philosophical text. However, existing forms of

${ }^{12}$ The Starry Messenger was immediately recognized as an important work: the Venice edition of 550 copies sold out quickly and a Frankfurt edition was published the same year.

${ }^{13}$ Galileo, 1890-1909, 10:297-99.

${ }^{14}$ Stevens, 116-18.

${ }^{15}$ Galileo, 1890-1909, 10: 305.

${ }^{16}$ For an overview, see Drake, 1978, 157-76.

${ }^{17}$ For a complementary rhetorical analysis that emphasizes the experiential qualities to The Starry Messenger, see Moss, 83, 76-85. 
philosophical discourse such as dialectical reasoning, geometric proof, and citation of authorities did not incorporate visual observation as a primary form of proof or argumentation. ${ }^{18}$ Galileo, by contrast, wanted to construct The Starry Messenger so that it reflected this new technology of observation. Consequently, he adopted a style and format that would enable readers to become active participants in the process of observation.

The Starry Messenger - a peculiar combination of narrative, journal, and picture book - is designed to make the experience of reading the text resemble as much as possible the experience of looking through the telescope. In this context, the most notable textual feature of The Starry Messenger is its illustrations: the 1610 Venice edition, which has only thirty leaves, contains more than seventy drawings and diagrams. In their combined force these images show readers versions of what Galileo had observed in the sky. The illustrations - and the visual presentation of the text - are distinctive in two ways. First, in contrast to the work of astronomers such as Johannes Hevelius, Galileo's illustrations are not attempts at naturalistic realism. ${ }^{19}$ As critics have noted, for example, the craters on Galileo's moon are exaggerated more than might be expected, even taking into account the limitations of his equipment. ${ }^{20}$ While it would probably be going too far to say that Galileo deliberately introduced distortions into his engravings as a way of underlining the necessary distortion of the telescope, it is nonetheless clear that Galileo's primary concern was not realistic "accuracy." At the same time, he does not use his illustrations as reading aids either. Scientific illustrations in works such as Peter Apian's Cosmographia, for instance, are essentially sophisticated versions of a "pointing hand" marker: their primary function is to provide visual confirmation that refers back to the text. Thus, scientific illustration in this period ranged from realistic naturalism to the kind of schematic textual illustration employed by Apian: one illustrated either the world or the text. Galileo, however, conceives of his illustrations as

${ }^{18}$ Unlike the philosophical disciplines, many of the so-called mechanical arts did rely heavily on both visual observation and pictorial illustration - herbals are a particularly good example of this practice. Having studied at the Accademia del Disegno in Florence where the curriculum focussed on the mechanical arts (applied mathematics, mechanics, visual arts, and design), Galileo was certainly aware of this important tradition. However, as Biagioli has demonstrated, Galileo recognized that because mathematics was allied with the mechanical arts, it had a lower status than the "philosophical disciplines" (Biagioli, 1993, 2-3, 6-7). Galileo's desire to find a new way of using images is thus consonant with his interest in imagining and defining for himself a position as a new kind of "court" philosopher.

${ }^{19}$ For a discussion of Hevelius's work in this context, see Winkler and Van Helden, 1993; on the connection between optics and realistic naturalism in painting, see Alpers, 1-71, and Kaufmann.

${ }^{20}$ Gingerich, 77-88; Drake, 1978, 145. 
viewing aids because he wants to convey how the new way of seeing demanded by the telescope also transforms the ways that readers will encounter textual accounts of this seeing. Galileo does not want to reproduce the image he sees in the telescope; rather, he makes The Starry Messenger into a kind of textual telescope for his readers so that his readers will experience this new way of observing as a new way of reading. Recognizing that the technology of the telescope augments the observer's vision, Galileo exploits the technology of printing and engraving to enhance the reader's ability to see by means of the text.

Galileo's strategy for making the text into a visual tool that functions like a telescope can be seen in the way that he illustrates the constellations. Traditionally, the constellations were understood as visible, but partial, manifestations of cosmic truth. Classical myths about the constellations are explicit versions of the belief that the heavens provide visible expression of the otherwise invisible order of the world. Although the cosmography behind such myths had largely disappeared, the underlying conception of the celestial universe had not. Thus, Tintoretto's "Origin of the Milky Way" (ca. 1580 ) represents the stars in the constellations being created as milk flowing up to the sky out of Juno's breasts (fig. 1). While Tintoretto's work is mythological, scientific star charts also adhere to the same conventions: in the first Renaissance star chart (1512-1515), Albrecht Dürer inscribes the stars of the northern and southern hemisphere inside figures representing such myths as the story of Juno's transformation of Callisto and Arcas into Ursa Major and Minor. The point is not that illustrators "believed" that either Juno's milk or her jealousy produced the stars. Rather, these images of the heavens depict celestial bodies as a visible expression of the otherwise invisible order of the universe. ${ }^{21}$

Galileo's illustrations, by contrast, recognize this tradition of artistic and scientific illustration in order to revise it. Galileo was knowledgeable about contemporary artistic theory; as Eileen Reeves has shown, he had taken lessons in perspective which subsequently led to his long friendship and intellectual collaboration with painters such as Lodovico Cigoli. ${ }^{22}$ Galileo wanted to demonstrate in The Starry Messenger that what human eyes could see of the heavens was indeed limited, but not in the ways that the Greeks or previous illustrators thought. Where before most observers could see six stars in Taurus, Galileo could now distinguish thirty-five; Orion went from

${ }^{21}$ Court artists often made use of this fundamental belief when they represented the heavens as a celestial sign confirming the power of a ruler. See Rash-Fabbri; Biagioli, 1993, 139-49.

${ }^{22}$ Reeves, 6, 18-22; see also Panofsky, 4-7, and fig. 2. 

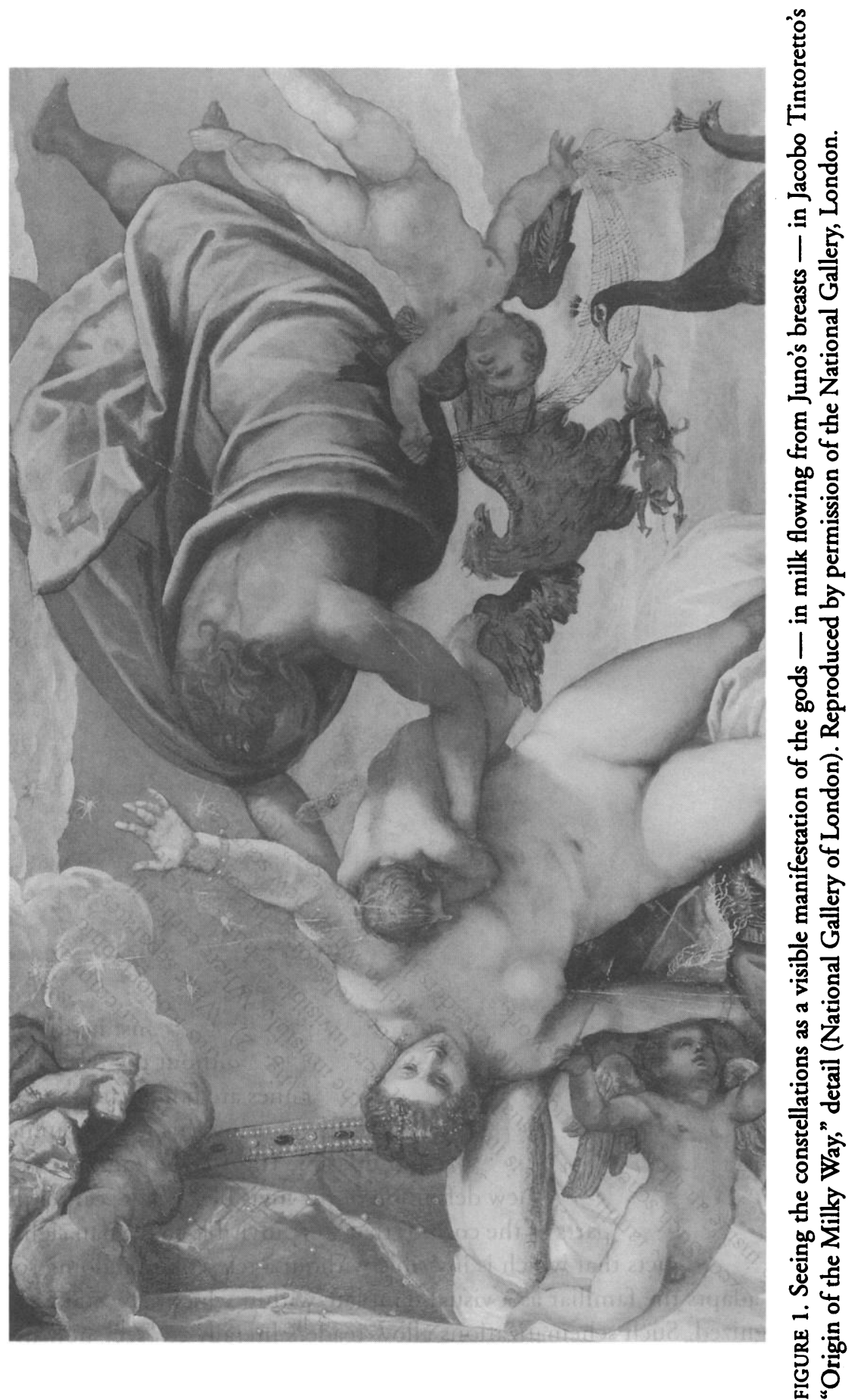


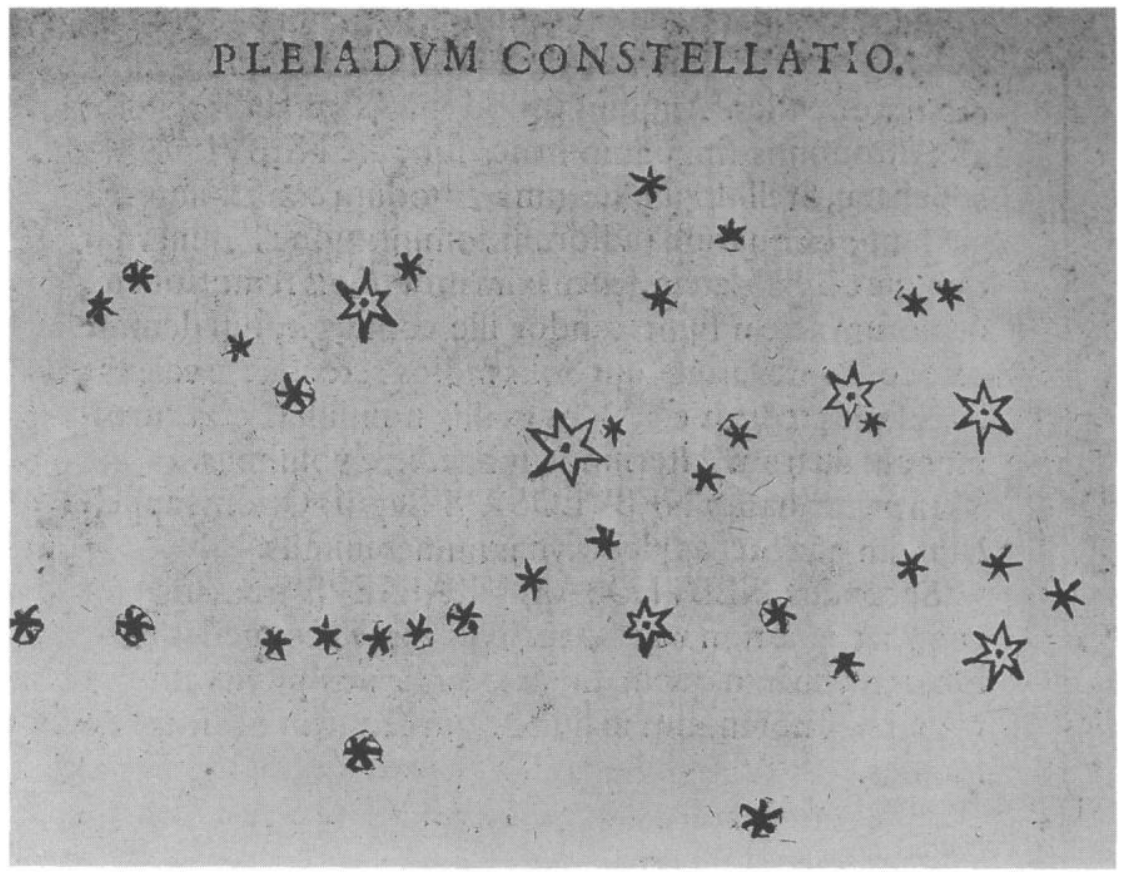

FIGURE 2. Seeing the constellations as a phenomenon made visible by the telescope in The Starry Messenger. Reproduced by permission of the Houghton Library, Harvard University.

nine stars to eighty. Galileo acknowledges that it is hard to imagine so many "new" stars: "with the glass you will detect ... such a crowd of others that escape natural sight that it is hardly believable .... But in order that you may see one or two illustrations of the almost inconceivable crowd of them, and from their example form a judgment about the rest of them, I decided to reproduce two star groups" in illustrations (59). In these illustrations, Galileo revises traditional techniques used to represent the constellations: he draws double outlines around the stars that had been visible without the telescope "for the sake of distinction" (61). The double outlines are not an attempt at "realism"; as with Tintoretto and Dürer, Galileo is using this iconographic device to distinguish between visible and invisible (fig. 2). What separates Galileo's work, however, is a new definition of the invisible. Where earlier illustrators had shown parts of the cosmos that were invisible to human sight, Galileo now depicts that which is invisible without a telescope. In doing so, Galileo adapts the familiar as a visual template within which new stars can be recognized. Such schematizations allow readers literally to "see" new information inside an identifiable framework. 
Galileo is one of the first astronomers to publish accounts of his work with the telescope. He is also one of the first astronomers to make pictorial illustration a substantial part of his texts. ${ }^{23}$ Yet, as Mary Winkler and Albert Van Helden make clear, one cannot thus "conclude that the practice of illustrating astronomical texts with pictures carrying information essential to the argument came into astronomy quite naturally as a concomitant of the telescope" $(1992,197)$. In The Starry Messenger, the reader experiences the text as a form of reading compatible with the new way of seeing achieved by the telescope. The radical nature of Galileo's textual practices can be seen by comparing the 1610 edition of The Starry Messenger to later seventeenthcentury editions of Galileo's work. In the original Venice edition, for example, Galileo's illustration of the constellations was added at the last minute on a separate sheet bound into the book. ${ }^{24}$ This illustration is designed to make readers see the "almost inconceivable" quantity of new stars: allowing the stars to extend out past the margin and into the gully of the page, Galileo reproduces, however partially, some sense of the vast heavenly panorama. Pierre Gassendi's 1655 Institutio astronomica reissues The Starry Messenger with a return to a more conventional understanding of the role of the reader. In keeping with the traditional range of scientific illustration, his woodblock prints are at once both more "realistic" and yet also more "textual" than the Venice edition. ${ }^{25}$ The edition is more realistic in the sense that Gassendi has the constellations printed as white stars on a black "sky" background; it is more textual in inserting those plates in a separate section at the end of the book, blocked with careful borders and labelled with identifying titles. Although later editors like Gassendi revert back to the dominant types of textual illustration, Galileo uses the illustrations to make it easier not just to read, but to see.

Galileo's departure from the conventions of current scientific publishing can similarly be seen in the first illustration in the text, an unusually elongated diagram of the telescope which extends past the text margin and 3/4" beyond the edge of the normal page width. As a result, the point that represents the "eye" of the telescope viewer is set in the margin. Where many illustrations may be no more than typographic renderings of a reading aid, this diagram is an image of the relationship between the telescope viewer and the text reader. The telescope stretches out beyond the text; the reader

${ }^{23}$ Van Helden, 1977.

${ }^{24}$ The sheet, which is not paginated or marked in the signature, has been inserted after D1; the collation for the volume is A-C4, D6, E4.

${ }^{25}$ Gassendi's edition, although a quarto volume, is of reasonably good quality. Similar claims can be made about other seventeenth-century editions: the Frankfurt edition of 1610 uses woodcuts; the Bologne 1656 edition of Galileo's works makes similar editorial decisions. 
and the viewer's sites are aligned but not identical. Later editions of the text reprint this first diagram, but transform it into a more conventional image. In the Gassendi edition, again, the diagram has been compressed and reoriented so that it runs down the page vertically. As a result, Gassendi's drawing is no longer natural for the reader in the sense that the sight lines now run perpendicular to the reader's perspective rather than parallel to it. The text itself acknowledges this new discrepancy, that the reader is no longer a viewer. Where Galileo marked the place of the eye with a letter, an iconic "eye" has been inserted in Gassendi's text, looking down the page, as if to reinforce the lesson.

While most scientific texts continue to adhere to existing understandings of the role of the reader until the eighteenth century, Galileo's close supervision of the publication process allowed him to produce a book that reflected his new understanding of the role of the reader. In The Sunspot Letters (1613), again, it is not just the observational technology that is new: the text is written, illustrated, and published in a format that reflects Galileo's underlying philosophy about the reader's relationship to these new kinds of observations he is making. The telescope literally produces both the observations and the text for The Sunspot Letters. The text contains a sequence of thirty-eight full-page illustrations which chart the movements of sunspots across the surface of the sun. These illustrations - whose production Galileo discusses at length - were made by directing the telescope at the sun, putting a piece of paper at the other end of the telescope, and tracing out the images on the paper. As a result, readers see both what and how Galileo saw; by using the telescope itself as a mechanism for producing these tracings, it becomes possible to see sunspots "without damage to the eye ... which, when observed through the telescope, can scarcely be perceived, and only with fatigue and injury to the eyes." 26 Since Galileo himself did not look through a telescope to see the sunspots, there is no image to be reproduced. Thus, the text cannot be a representation of what Galileo saw; instead, it strives literally to be what he saw. Galileo becomes a reader of his own textual tracings. In this case the process of being an observer and that of being a reader are basically identical. In departing from the conventions of both contemporary art and book-making, Galileo uses illustrations to make looking at the text a visual activity that produces knowledge for the reader. Like the telescope itself, these texts become tools that make it possible to see things otherwise invisible - or dangerous - to the human eye.

Galileo's interest in defining a new type of reader also informs his decision to publish The Sunspot Letters in Italian rather than Latin. In part,

${ }^{26}$ Galileo, "The Letters on Sunspots" in Drake, 1957, 115. 
Galileo uses the vernacular because he is writing primarily to the court world rather than to the international scholarly community. ${ }^{27}$ Galileo nonetheless explains this decision in terms that reflect his understanding of reading as an act of seeing:

I wrote in the colloquial tongue because I must have everyone able to read it .... Now I want them to see that just as nature has given to them, as well as to philosophers, eyes with which to see her works, so she has also given them brains capable of penetrating and understanding them. ${ }^{28}$

This passage is curious in that it seems to run counter to Galileo's claim that the telescope is necessary precisely because man does not, in fact, have the "eyes with which to see" nature's works. Yet, the arguments that he is making for using the vernacular are both justified by and support his arguments for using the telescope. Galileo adapts the conceit that nature is a book as a way of juxtaposing his "vernacular" philosophy with the abstruse works of ordinary philosophers. Galileo suggests that Latin and, by implication, the older forms of philosophical discourse that accompany it obscure the truth. By writing in Italian, however, Galileo uses a new language that is appropriate to his new scientific technologies. Reading in Italian and seeing through the telescope are, Galileo suggests, analogous activities in the sense that both are new ways of apprehending knowledge: they open up knowledge for everyone to see better and further.

Galileo's commitment to defining a readership appropriate to this new knowledge can likewise be seen in his request that Ludovico Cigoli see The Sunspot Letters through the press for him. As a painter who had studied with Galileo at the Accademia del Disegno in Florence, Cigoli was committed to integrating the visual experience of Galileo's observations into the text. Responding to a professor from Rome who suggested that what Galileo thought were mountains on the moon were really opaque shapes being seen through a crystalline shell, Cigoli wrote that "I find no excuse for him except that a mathematician, however great, without the help of a drawing, is not only half a mathematician, but also a man without eyes." 29 As Cigoli suggests, without the illustrations many readers are unable to see, let alone understand, Galileo's claims. This attention to the reader's participation in a kind of textual observation is suggestively raised in the engraved portrait of Galileo included in the front matter to the 1613 edition of The Sunspot

\footnotetext{
${ }^{27}$ Biagioli, 1990, 60-73.

${ }^{28}$ Letter to Paolo Gualdo in Galileo, 1890-1909, 11:327.

${ }^{29}$ Letter to Galileo in Galileo, 1890-1909, 11:167-8.
} 


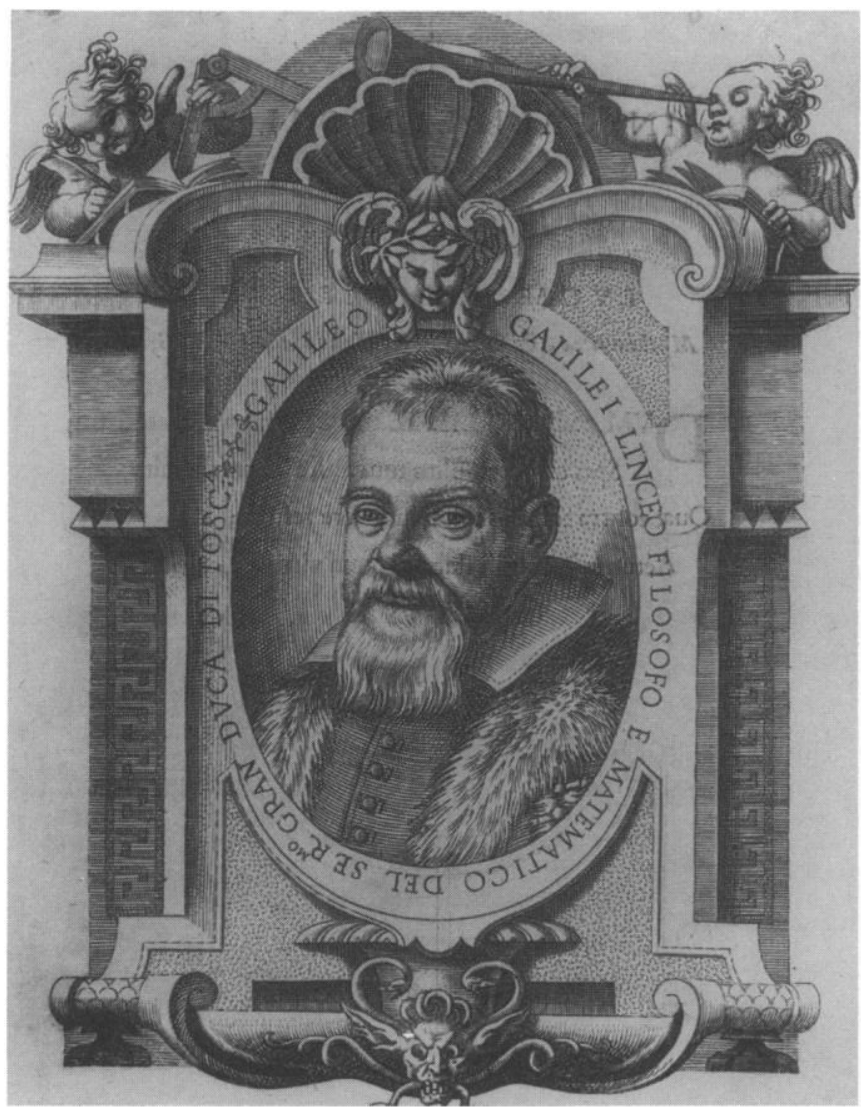

FIGURE 3. Engraved portrait of Galileo, flanked by astronomical cherubim, from The Sunspot Letters. Reproduced by permission of the Houghton Library, Harvard University.

Letters (fig. 3). ${ }^{30}$ Perched on a baroque facade above a portrait of Galileo are two cherubim with open books. The left-hand cherub, a figure for the kind of traditional observational astronomy exemplified by Tycho Brahe, holds a quadrant and bends over the book writing. The right-hand cherub, by contrast, simply holds his book in his hand, as he peers through the end of a long telescope with one eye closed. Framing Galileo and his work, the two cherubim represent different aspects of astronomical research - on the right, charting new stars, as Brahe did, by using the quadrant; on the left, seeing new stars, as Galileo did, with the telescope. This illustration links older forms of astronomy to writing, but connects the new astronomy of the telescope to reading.

${ }^{30}$ This portrait has been attributed to Francesco Villameno, but see Fahie, 13-16. 
As an image of historical developments in astronomy, this engraving depicts the transition from a traditional emphasis on the authority of the writer to the new importance in Galileo on the experience of the reader. In part, the suggestion may be that in traditional astronomy, theory and writing occurred before or at least independent of observation while, with the telescope, they occur after it. The astronomy represented by the cherub on the right involves two kinds of new knowledge: the power of the telescope and the power of the reader. The addition of the reader to this picture is as important as the addition of the telescope because for Galileo the reader as much as the telescope is integral in creating new knowledge. In Galileo's "new astronomy," man can now see that which was previously invisible with what Milton identifies as the "ken" of angels - and can do so either by looking through the telescope or by reading.

Galileo's attitude towards his readers arises, in part, out of his need to use observation to demonstrate truths that he could not prove mathematically. As this analysis has suggested, Galileo puts the reader in the position of the observer by making reading into a form of experience in The Starry Messenger and The Sunspot Letters. At the same time, however, one might argue that it is not so much the reader who is an observer for Galileo as it is the observer who is a reader. As Timothy J. Reiss demonstrates, Galileo ultimately concludes that the only way of achieving certain proof is through mathematics. ${ }^{31}$ Thus, in The Assayer (1623) Galileo argues:

Philosophy is written in this grand book, the universe, which stands continually open to our gaze. But the book cannot be understood unless one first learns to comprehend the language and read the letters in which it is composed. It is written in the language of mathematics, and its characters are triangles, circles, and other geometric figures. ${ }^{32}$

For Galileo, the Book of Nature is the only true text and this text is written in the language of mathematics. In figuring the true philosopher as a "reader" of nature, Galileo is explicitly critiquing traditional Aristotelians, such as Horatio Grassi, who practice philosophy by reading the texts of "authorities." Yet, perhaps less obviously, Galileo's argument also encompasses the activities of those who would claim to produce the truth through experiment and observation. These philosophical practices fall short because they do not recognize that seeing is not enough: although nature may be "open to our gaze," it cannot be comprehended except through the language and knowledge of mathematics. Where the philosopher Grassi might mistakenly believe that the "true" text is to be found in Aristotle rather than in nature,

${ }^{31}$ Reiss, 1977, 19-26. See also Reiss, 1997, 109-31.

${ }^{32}$ Drake, 1957, 237-38. 
experimentalists and observers are equally wrong when they fail to recognize that nature is itself a "text."

Instead of making readers equal to observers, Galileo's conclusions in The Assayer thus effectively problematize the position of both observers and readers. Texts and observations finally have for Galileo the same epistemological status: they can persuade and confirm, but they cannot create the truth. Galileo uses the example of literature to make this point about Grassi's work:

Possibly he thinks that philosophy is a book of fiction by some writer, like the Iliad or Orlando Furioso, productions in which the least important thing is whether what is written there is true ... . [Grassi] acts as if acquainted with neither nature nor poetry. He seems not to know that fables and fictions are in a way essential to poetry, which could not exist without them. ${ }^{33}$

Although Galileo's remarks are obviously an attack on the writings of contemporary Aristotelians, he would also make the same argument about his own texts. Galileo understands that Homer's Iliad, Grassi's Astronomical and Physical Balance, and his Starry Messenger are alike in that they are what Reiss identifies as "didactic" texts: they seek to persuade readers $(1977,19)$. It is not that such texts are lies; they simply do not have an essential connection to the truth. Because such texts seek to persuade readers, they must rely on what Galileo refers to as "fables and fictions." "Fables and fictions" are the distortions, mediations, and acts of interpretation that writers use to persuade readers.

In adopting this position, Galileo's philosophy differs in important ways from that of empiricists such as Robert Boyle. As Steven Shapin and Simon Schaffer have demonstrated, Boyle used many of the same narrative techniques beginning with his New Experiments Physico-Mechanicall (1660) as a way of creating a reader who could assent to his experimental claims. Their crucial point is that readers in the early modern period became increasingly important to scientists because they represent potential witnesses. They identify Boyle as the initiator of a revolution not simply in scientific practice but in scientific discourse when he defines the knowledge obtained by reading as a form of "experience," a low-grade but nonetheless acceptable form of truth. ${ }^{34}$ Yet, it is important to recognize that when Boyle credits readers with access to the truth, he does not just solve the problem of limited access to experimental sites. In doing so, Boyle also solves the more basic problem - confronted earlier by Galileo - of how reading can be valid in a scien-

${ }^{33}$ Ibid., 237-38.

${ }^{34}$ Shapin and Schaffer, $1985,55-65$. For accounts, by contrast, that emphasize the ways in which even the most innovative natural philosophers - when they themselves read - reverted to and relied upon precisely the reading techniques developed and practiced by humanists, see Blair, Grafton. 
tific culture that put so much emphasis on personal experience. Earlier empiricists such as William Harvey had said that, as a reader, all you could get was a "tumid and floating opinion ... never a solid and infallible knowledge." Boyle, by contrast, claims that readers can obtain "as distinct an Idea" from reading as they could in conducting their own experiments. ${ }^{35}$ By speaking of distinct ideas, Boyle thus argues that reading is itself a personal "experience" and can produce at least a version of the truth that observers discover through experiment.

Like Boyle, Galileo recognizes that knowledge derived from reading is inherently mediated: in both argument and form, The Starry Messenger tries to answer the complaint that looking at a text is not the same as looking through a telescope. In contrast to Boyle, however, Galileo also faces a second problem in creating belief for readers. In Galileo's case, it was not just the knowledge that comes through the text that is mediated; the knowledge produced by the telescope itself is also problematically indirect and uncertain. What Galileo attempts - in both The Starry Messenger and The Sunspot Letters - is not the empirical project of claiming that what can be seen is true. Rather, Galileo wants to make claims - about the moon, the Medicean stars, the constellations - that cannot be seen except through the instrument of the telescope. Galileo recognizes the fundamentally parallel nature of these two kinds of mediation. In The Starry Messenger Galileo takes the problems faced by any reader of any observational text and conflates them with the particular problems inherent in using the telescope as a tool for observational astronomy. In presenting his evidence, Galileo suggests that solving the problem of the way that knowledge is mediated through the text will also solve what is for him the larger problem of how knowledge is mediated through the telescope - or in any other observational situation.

Important here is the way in which the two problems - one which might be called literary and the other scientific - become interdependent. If Shapin and Schaffer show us through Boyle a solution to Galileo's need to compensate textually for the mediation caused by reading, what remains to be seen is the solution to the philosophical problem of the mediation produced by the telescope itself. As we shall see, Margaret Cavendish's Blazing World should be understood as the logical consequence of and conclusion to the problem that Galileo has with the limitations of the telescope as a technology that relies on mediation for its knowledge. What Cavendish solves is, ironically, not the specifically textual problem of how to give readers access to observations. Instead, The Blazing World confronts the more fundamental philosophical problem of the mediated relationship that observers and ex-

${ }^{35}$ Harvey, fol. 91v-2r; Boyle, fol. A4r. 
perimental scientists have with the truth. Like Galileo, Cavendish depicts for readers something that they cannot see - something not visible to the naked eye. That something is fiction, not science. The point is not just, as critics have suggested, that Cavendish uses science to construct her fictional world, nor, as others have suggested, that Cavendish uses fiction to illustrate her philosophical precepts. ${ }^{36}$ Extending these partial arguments to their logical conclusion requires us to take Margaret Cavendish seriously and recognize that the fiction itself is the philosophy. Both in argument and form, The Blazing World offers one solution to Galileo's philosophical problem about the limits of observation. When we look at Cavendish looking, in effect, through Galileo's telescope, we see that she has redefined that which exceeds the natural limitations of human vision as the realm of fiction. As is clear in The Assayer, Galileo ultimately rejects experiment and observation as a source of true knowledge and turns instead to mathematics. Cavendish likewise rejects experiment and observation, but replaces it with an understanding of fiction as experience. What Galileo and Cavendish share is a similar understanding of the problems inherent in the relationship between readers, observations, and reality. Their different responses assume significance as a defining moment in the emerging cultures of science and literature.

Although Cavendish's critique of the limitations of human vision has many dimensions, it should be pointed out that her gender affects how well she can see the claims of natural philosophy. She is a representative of the reader who had almost no access to the experimental site - to the laboratories, anatomy theaters, scientific societies, or universities. Where recent social histories of science have emphasized the way that class could determine the pursuit of truth, it also is important to remember that the etiquette of experimentalism did not cut across gender lines. As the progression of her texts suggests, Cavendish's primary means of participating in contemporary scientific and philosophical debate over experimentalism in the 1660 s was as a reader. As we shall see, Cavendish challenged not simply telescopes, microscopes, and other "artificial devices" of contemporary optics, but she also implicitly objected to the impact that these new ways of seeing had on her as a reader.

${ }^{36}$ Most critics understandably make a choice in either subordinating science to literature, or literature to science. For readings that emphasize the ways in which Cavendish's work is a fictional illustration of different scientific concepts see Rogers, 177-211; Sarasohn, 289307; Stevenson, 527-43; Battigelli. Kegl, 126, makes an argument similar to mine when she suggests that The Blazing World is a piece of "Fancy" which is "attached" to The Philosophical Observations in order to show readers that fancy, as a contemplative activity, is the final stage of philosophical inquiry. 
Drawing on a tradition of speculative moral philosophy, early works such as the Philosophical Fancies (1653) and the Philosophical and Physical Opinions (1655) rely primarily on what Cavendish refers to as "rational thought," deductions based on her "sense and reason" rather than on outside sources. After engaging in what she represents as an intensive programme of reading in scientific subjects, though, Cavendish writes her Philosophical Letters (1664) and Observations upon Experimental Philosophy (1666). Adopting the perspective of a reader responding to ongoing intellectual debates, the Philosophical Letters addresses questions of speculative moral philosophy in the works of Hobbes, Descartes, and others, while the Observations considers the new experimental philosophy advocated by Hooke, Boyle, and the Royal Society. Yet, what distinguishes these later works from one another is not simply their subject matter. While the tradition of philosophy that Hobbes represented might in theory make a place for Cavendish's writing, experimentalism did not. In the Philosophical Letters, Cavendish thus uses reading as a way to enter more fully into philosophical debate - to enable her transformations into a writer. In the Observations, by contrast, Cavendish confronts the ways in which experimental philosophy might allow her to be a reader, but only did so by excluding readers from full participation in the practice of science and creation of knowledge. As a result, even as Cavendish's thought develops in this period, she never seeks to become an experimental philosopher or to write her own work of experimental philosophy. Rather than completing the $O b$ servations she makes against experimental and observational philosophy with her own work in this area, Cavendish thus ends her text with the anti-experimental fiction of The Blazing World.

If Galileo faced the problem of trying to communicate the experience of what he saw to his readers, Cavendish responds as a reader who found observational accounts such as The Starry Messenger ultimately inadequate as a substitute for experience. Thus, just as Galileo's departure from established forms of scientific exposition in The Starry Messenger was the product of his position outside the highest ranks of philosophers, so is Cavendish's skepticism also a product of a more extreme exclusion from the scientific world. Cavendish's antagonism towards contemporary scientific practice is most evident in her understanding of what it means to be a reader. As Steven Shapin has pointed out, the early scientific laboratories were located primarily in private homes so that "access to experimental spaces was managed by calling upon the same sorts of conventions that regulated entry to gentlemen's houses" (389). Yet, women who would have been admitted to drawing rooms rarely entered the laboratories and alchemical closets of those same houses. In Margaret Cavendish's case, it was only her noble standing and her brother's 
connections that made it possible for her to visit the Royal Society. ${ }^{37}$ And even then, Cavendish's single visit only underlined her exclusion from the experimental site; ordinarily, as Shapin argues, entrance imposed an obligation to participate by acting as a witness to demonstrations. Cavendish clearly did not participate when she went to the Royal Society; instead, Cavendish saw only a spectacle of which she herself was a central part.

Cavendish's sense of herself primarily as a reader can be seen in her attitude towards her own readers. Cavendish exultantly wished for readers, hoping that she might have not just one reader to praise what she wrote, but rather "a Thousand, or rather Ten thousand Millions, nay, that their numbers were Infinite" $(1664,163)$. Cavendish's almost obsessive interest in reaching an audience through her works is reflected in the elaborate prefatory materials of her books; The Philosophical Fancies, for example, is introduced by three different letters, each invoking a different kind of reader. Where Galileo is forced to seek patronage from court figures such as Cosimo de' Medici, Cavendish uses her social standing to act as her own patron. Instead of sending copies of her books to courts as Galileo does, Cavendish depends on her social position to have her lavishly published folio editions placed in major libraries and with eminent philosophers. ${ }^{38}$ Cavendish's interest in reaching readers is not so much an expression of an egocentric desire for fame as it is a recognition of how central her own experiences as a reader were in defining — as well as limiting — her understanding of the world.

The Blazing World was one of a series of works in which Cavendish tried to invent a perspective to critique the emergent, experimentally-oriented natural philosophy which she knew as a reader. For Cavendish, fiction provided the consolation that philosophy could not bring. The Blazing World transforms her critique in the Observations upon Experimental Philosophy of reliance upon sensible perception as a source of knowledge and extends it into a poetic theory. Expressing a conservative resistance to the dissociation of seeing from knowing, Cavendish attempts to close the space that opens up between the scientist's assured sight of the truth and the reader's less direct apprehension of it in the text. Cavendish uses the utopia, rather than a more realistic genre, to make this critique precisely because utopias are structured to represent a disparity between an "actual" and an "ideal" world. As Fredric Jameson suggests, utopias typically use a frame narrative to mediate this gap between ideal and actual. ${ }^{39}$ In this case, Cavendish figures her frame narrative as a telescope to make reading "through" the frame like looking

\footnotetext{
${ }^{37}$ See Mintz.

${ }^{38}$ Grant, 218-20.

${ }^{39}$ Jameson, 78-80. See also Marin, 33-60.
} 
through a telescope into the "experience" of the central text. Cavendish's text does not simply talk about telescopes; it is structured like a telescope. In doing so, Cavendish is able to take readers out of the actual world as it is defined by experimentalists and other natural philosophers to offer an ideal that she finally suggests is "truer" than reality itself.

In moving from the more conventional romance narratives of her earlier stories to what she understands as a kind of new fictional truth, Cavendish uses astronomy to define the boundaries of her Blazing World. ${ }^{40}$ Modeling the experience of reading on that of looking into the telescope allows Cavendish to define her fiction in a way that also questions astronomy's reliance upon unverifiable visual evidence. Adhering to the patterns of earlier stories such as her "Assaulted and Pursued Chastity" (1656), Cavendish begins her narrative as a kind of prototypical romance in which a young man, "travelling into a foreign Country, fell extremely in Love with a young Lady" (1). Fleeing from the young man's attempt to kidnap her, the Lady travels further and further north until her boat passes through the north pole into another world called the Blazing World. This "northern passage" critically transforms both the geographic and generic boundaries of Cavendish's fictional world. Cavendish thus addresses readers who might "scruple" at her account of the Blazing World and its twin planet:

if it were thus, those that live at the Poles would either see two Suns at one time, or else they would never want the Suns light for six months together, as it is commonly believed; You must know, that each of these Worlds having its own Sun to enlighten it, they move each one in their peculiar circles; which motion is so just and exact, that neither can hinder or obstruct the other; for they do not exceed their Tropicks, and although they should meet, yet we in this world cannot so well perceive them, by reason of the brightness of our Sun, which being nearer to us, obstructs the splendor of the Suns of the other Worlds, they being too far off to be discerned by our optick perception, except we use very good Telescopes, by which skilful Astronomers have often observed two or three Suns at once. (3, emphasis mine)

In the opening pages, readers would already expect the Blazing World to be an alternative romance world. With this direct address to the reader, however, Cavendish introduces a new world into her fiction - not the Blazing World, but the Lady's native world. Prior to this point in the text, there is nothing to indicate that the Lady's world, "the world," is not some version - however fictionalized - of our world. If the dualism of romance generally suggests some divide between the truth of reality and the

\footnotetext{
${ }^{40}$ For examples, see Cavendish, 1992; on Cavendish's attitude to romance, see especially Kahn.
} 
ideal that is fiction, Cavendish introduces a third planet into her fiction as an alternative, as a way of suggesting how we might move beyond the limitations of those existing possibilities.

Cavendish's account of the suns that "enlighten" these planets starts out as a way of asserting the plausibility of her narrative world. As such, it can be understood in the context of disclaimers such as the proem to Book 2 of The Faerie Queene in which Spenser defends his account of Faerieland against those who suspect that what he describes is only "painted forgery." Yet, as Cavendish continues the emphasis shifts from what they see to how we see. It thus becomes clear that it is not improbable planetary motions that are a problem; at issue rather is our ability to know anything about such a world. Cavendish's suggestion that the worlds she describes are real but not visible "except we use very good Telescopes" initially situates this utopia just beyond the range of unaided vision. Science - the knowledge of "skilful Astronomers" - appears to provide the most certain access to and confirmation of her fictional realm. Yet, as soon as Cavendish allies this world with scientific discoveries, she critically qualifies that connection. The suggestion that astronomers could see the Blazing World through their "very good Telescopes" in the same way that they sometimes see "two or three suns at once" transforms scientific discovery into optical illusion. What science can attest to is no more than a disappearing parahelion. Even as the frame narrative models reading on the act of looking through the telescope, Cavendish insists that it is not astronomers with telescopes, but instead perhaps more "skillful" readers with texts who will be able to discover this strange new world.

Responding to her own experiences as a reader, Cavendish constructs The Blazing World to redefine the access that her readers have to the "truth" of the text. As critics have recognized, Robert Hooke's Micrographia (1665) provided a key impetus for Cavendish's fiction. ${ }^{41}$ Hooke's work might be seen as an intellectual consequence of Galileo's rethinking of the problem of scientific illustration: Galileo's comparatively crude "observations" with the telescope are in some sense completed by Hooke in his more detailed set of sixty "observations" that begin with the point of a needle and end, appropriately, with a view of the moon. ${ }^{42}$ Yet, if Galileo attempted to create a new technology for reading as part of the visual culture of science, Hooke's "observations" differ in that their microscopic realism ultimately limits the reader. As Cavendish understood it, the Micrographia allowed the reader to see only as much as its "observations" showed; the very elaborateness - in both text and engraving - merely emphasizes how what the author saw became a sub-

${ }^{41}$ E.g., Battigelli.

${ }^{42}$ Gunther, 13:1-4; 242-46. 
stitute for, rather than an encouragement to, experience itself. Hooke is thus in some sense aligned not so much with Galileo's textual practices as with those of literary writers who responded to new visual technologies by using their texts to show readers - if often parodically - what you could see through the telescope. John Donne thus imagines that Galileo is able to bring the moon to the earth in Ignatius, his Conclave (1611), while Francis Godwin's Man in the Moone (1638) depicts a world of people ten, twenty, and thirty times larger than life. Even as they satirize the power of the telescope in ways that point to its inherent distortions, Donne and Godwin nonetheless replicate in a literalized narrative form the augmented vision of the telescope.

In The Blazing World, by contrast, Cavendish intends the reader to see things which would not be visible in any lens, however powerful. Instead of mimicking the increased magnification of the telescope, Cavendish shows in her fiction how the telescope can decrease the range of man's sight. The implications of this more limited range of the telescope can be seen in Cavendish's description of the inhabitants of this world. Of "several Complexions," the people of this land are a kind of rainbow of skin colors: "some appear'd of an Azure, some of a deep Purple, some of a Grass-green, some of a Scarlet, some of an Orange-colour" (14-15). Where the races and peoples encountered by various new world explorers were only "white, black, tawny, olive- or ash-coloured," Cavendish imagines a vivid alternative in the "severall Complexions" of the people inhabiting her new world. Although Cavendish here participates in a larger seventeenth-century practice of identifying skin color as a key mark of race, the primary concern of this passage is neither race nor ethnography. ${ }^{43}$ The range from white to ash to olive, tawny, and black describes not just human skin color; it also captures the comparatively monochrome qualities to what could be seen at high magnifications through early telescopes. By contrast, the colors that Cavendish imagines - "Azure," "Purple," "Grass-green," "Scarlet," and "Orange-colour" - brilliantly refract the full range of visible light. Implicitly a product of natural vision, the people of this world represent something that simply cannot be seen through the artificial methods of the telescope. Coloring the people, their palaces, and the land itself "like so many Rainbows," this spectacle of light becomes a symbol of the majestic power of Cavendish's world (12). Where before the telescope would allow astronomers to see the Blazing World only as an illusory parahelion, now in its inability to show more than a monochrome, the telescope with its artificial vision misses the magnitude and power of this "Blazing" world.

${ }^{43}$ On how Cavendish here rethinks earlier reactions to the racial categories identified by Samuel Purchas, see Spiller, 162-3; cf. Kegl, 135. 
While the construction of the Blazing World affirms the power of natural vision, the scientific practices of its inhabitants demonstrate the limitations to artificial technologies. When the Lady, becoming Empress, establishes learned societies to further knowledge, she finds herself consistently frustrated by the reliance of her scientists on various forms of uncertain visual evidence. In debates that ironize proceedings at the Royal Society, representatives of different societies are repeatedly forced to admit that they cannot answer the Empress's questions because they cannot see something. Astronomers cannot determine what air is because they cannot see it (22); chemists do not know whether all animals have circulatory systems because these interior motions are not visible "neither of themselves, nor by the help of any optick instrument" (35); natural philosophers are unable to observe "the interior, corporeal motions" of vegetables and minerals (41). In the same way that Cavendish addresses her Observations upon Experimental Philosophy to what she refers to as "Modern Experimentall and Dioptrical Writers," here Cavendish mentions the experimental philosophers and the astronomers both first and at greatest length. Together, these two methods of scientific inquiry epitomize what is for Cavendish the greatest weakness of contemporary science: reliance upon visual evidence. These debates thus allow both a critique of experimental science and a demonstration of the methodological superiority of what Cavendish referred to as "rational thought."

During the most contentious of these arguments, the Lady asks the philosophers what they can see with their telescopes from the southern pole of the Blazing World. The philosophers report that "three blazing stars appear there, one after another in a short time, whereof two were bright, and one dim" (26). What Cavendish's astronomers describe seeing from their southern pole corresponds closely with what explorers described of the stars seen from the southern hemisphere of earth. Giving the first account of this new sky in 1503, Amerigo Vespucci tells of seeing "in that sky three canopi, two indeed bright, the third dim." ${ }^{44}$ Although descriptions of the Southern Cross captured popular imagination, the constellations of the southern hemisphere were not the subject of the kind of serious scientific debate associated with Galileo's "new" contellations. ${ }^{45}$ Yet, it is at this moment - with this observation - that the Empress effectively breaks the glass of the telescope and orders a complete reformation of all the sciences on her world.

Why should such a scientifically insignificant question become the basis for determining the validity of natural philosophy? As the desire to break the telescope suggests, what interests Cavendish is not testing the truth of

${ }^{44}$ Vespucci, 9; cf. Hues, 112.

${ }^{45}$ See Dekker. 
science, but rather promoting her fiction as a competing form of truth. In this case, the description of these three stars is important primarily because of its filiation with another group of three celestial bodies, the three planets described in The Blazing World. In a convergence of poetics and astronomy, this constellation of three spheres - two brighter and one dimmer - is also an evocation of the three fictional worlds of this text - the twin planets and the earth. The Empresses' natural philosophers are not quite certain about what they see with their telescopes; the Blazing World and its twin planet are similarly celestial bodies that, Cavendish suggests, cannot accurately be seen through a telescope.

Cavendish uses astronomy to establish the boundaries of her fictional world and, in doing so, works to discredit astronomy's powers. The Lady's second celestial voyage in The Blazing World provides a further critique of the philosophical assumptions underlying natural philosophy. In this voyage, the Empress and Margaret Cavendish, her secretary and companion, decide to visit earth by travelling as souls in special vehicles. Arriving in England, the two women go to the Duke of Cavendish's house at Welbeck, where Margaret and the Empress enter the Duke's body and they all enjoy "pleasant" conversations and "harmless" sports (111). More than just an exposition of her philosophical materialism, Cavendish's depiction of "three Souls in one Body" represents a human analogue to the structures of three planets that make up Cavendish's world. ${ }^{46}$ These three corporeal souls - in their very materialism - evoke the three celestial bodies and the three intertwined planets that make up this fiction. What Cavendish has done is adapt the traditional cosmological theory of the correspondences between macroand microcosm into a new kind of poetic theory. It is not just that our selves are in our stars; rather, these correspondences between scientific knowledge (the Southern cross), rational expression (souls in rational conversation), and poetic creation (this fictional world) are part of a single process of selfrealization. These equivalences - which take you from exploration of the stars to recognition of the self - become a model for the personal appropriation of scientific knowledge and power that fiction makes possible for a writer - or a reader - like Cavendish.

When the Empress first expresses the desire for a secretary, her advisors tell her that she can call up another soul to assist her in her work. The image of Margaret Cavendish, the obviously autobiographical Empress, and her husband all enjoying a pleasant "conversation" in the Duke's body tends to produce critical embarrassment about Cavendish's writing. Yet, even here,

\footnotetext{
${ }^{46}$ Margaret Cavendish, Philosophical Letters; cited in Grant, 203. On Cavendish's curious brand of materialism, see Stevenson, 527-43 and Rogers, 177-211.
} 
Cavendish is redefining on her terms the end of philosophy. The Empress originally chooses Margaret Cavendish as her scribe because she is unable to get Aristotle, Galileo, or Descartes. Just as Cavendish's writing of this book differs from their writings, so does her philosophy. Cavendish's goal in The Blazing World is not to read and thus know what Aristotle or Galileo knew. Rather, philosophy should lead to a pleasant, speculative, and sometimes fanciful "conversation" between rational souls. As a text, The Blazing World is a hostile, defensive response to the technology and scientific methodology exemplified by the telescope. By setting her whole narrative in opposition to the new worlds being discovered by natural philosophers, Cavendish presents a radical choice between being a reader and being a scientist.

Recent studies in early modern criticism have enlarged our understandings of the categories of author and text. While analyses of considerable sophistication have helped us understand the historical context that surrounded the production and publication of early modern texts, it is perhaps surprising how little attention has been paid to the activity in which we ourselves are most engaged - reading. Although it is only one among a number of developments in optics and visual technology, the telescope exemplified the new visual culture of the seventeenth century. This visual culture was characterized by a new understanding of how we, as observers, are related to the world around us. What Galileo and Cavendish recognized was that all acts of seeing - whether through a telescope, in a pinhole camera, or simply with our own eyes - involve artifice, mediation, and a necessary distortion. In this philosophical context, what is true of ocular perception is by extension also true of cognitive apprehension. Changes in how reading is understood thus follow more general philosophical developments about perception as a whole. This new understanding of how we "see" has a lasting significance because it determines how scientific and literary culture defines who their readers are, what they do, and what kind of apprehension is possible in texts. After the early modern period, texts convey facts but cannot produce "knowledge." Reading and observation are not simply about the "real world"; rather, they are about our relationship to that world. Out of this recognition - shared by Galileo and Cavendish - comes what will ultimately be the modern assumption that all acts of observation are acts of reading. If the telescope was for the seventeenth century a metaphor for reading as an act of apprehension, reading has ultimately become for us a figure for perception.

TeXas Christian University 


\section{Bibliography}

Agrippa, Henry Cornelius. 1986. Three Books of Occult Philosophy. Trans. J.F. 1651. Hastings.

Alpers, Svetlana. 1983. The Art of Describing: Dutch Art in the Seventeenth Century. Chicago.

Battigelli, Anna. 1996. "Between the Glass and the Hand: The Eye in Margaret Cavendish's Blazing World." 16501850: Ideas, Aesthetics, and Inquiries in the Early Modern Era 9: 25-38.

Baxandall, Michael. 1991. Painting and Experience in Fifteenth Century Italy: A Primer in the Social History of Pictorial Style. 2nd ed. Oxford.

Biagioli, Mario. 1990. "Galileo the Emblem Maker." Isis 81: 230-58.

1993. Galileo, Courtier: The Practice of Science in the Culture of Absolutism. Chicago.

Birch, Thomas. 1968, reprint. History of the Royal Society. 1756. 4 vols. London.

Blair, Ann. 1992. "Humanist Methods in Natural Philosophy: The Commonplace Book." Journal of the History of Ideas 52: 541-61.

Blumenberg, Hans. 1987. The Genesis of the Copernican World. Trans. Robert M. Wallace. 1975. Reprint, Cambridge, MA.

Boesky, Amy. 1996. "Milton, Galileo, and Sunspots: Optics and Certainty in Paradise Lost." Milton Studies 34: 2343.

Boyle, Robert. 1665. New Experiments Physico-Mechanicall Touching the Air. Oxford.

Cavendish, Margaret. 1664. CCXI Sociable Letters Written By the Thrice Noble, Illustrious, and Excellent Margaret Cavendish. London.

1666. Observations upon Experimental Philosophy. To which is added, The Description of a New World, called the Blazing World. London.
1992. The Description of the Blazing World and other writings. Ed. Kate Lilley. Washington Square, NY.

Dekker, Elly. 1990. "The Light and the Dark: A Reassessment of the Discovery of the Coalsack Nebula, the Magellanic Clouds and the Southern Cross." Annals of Science 47: 529-560.

Digges, Thomas. 1571. A Geometrical Practise, named PANTOMETRIA. London.

Donne, John. 1611. Ignatius his Conclave. 1610. Trans. anon. London.

-1994. The Complete English Poems. Ed. C.A. Patrides. 2nd ed. London.

Drake, Stillman, ed. and trans. 1957. Discoveries and Opinions of Galileo. Garden City, NY.

1978. Galileo at Work. Chicago.

Fahie, J. J. 1929. Memorials of Galileo Galilei, 1564-1642. London.

Galileo, Galilei. 1610. Sidereus nuncius. Venice.

-1890-1909. Le Opere di Galileo Galilei. Ed. Antonio Favaro. 20 vols. Florence.

Gallagher, Catherine. 1988. "Embracing the Absolute: The Politics of the Female Subject in Seventeenth-Century England." Genders 1: 24-39.

Gassendi, Peter. 1653. Institutio astronomica juxta hypotheses tam veterum, quàm Recentorium. London.

Gingerich, Owen. 1975. "Dissertatio cum Professore Righini et Sidereo Nuncio." In Reason, experiment, and mysticism in the Scientific Revolution, ed. M. L. Bonelli and W. R. Shea, 77-88. New York.

Grafton, Anthony. 1992. "Kepler as Reader." Journal of the History of Ideas 52: 561-72.

Grant, Douglas. 1957. Margaret the First; a biography of Margaret Cavendish, 
Duchess of Newcastle, 1623-1673. London.

Gunther, R.T., ed. 1920-1945. Early Science at Oxford. 15 vols. Oxford.

Harvey, William. 1653. Anatomical Exercitations, Concerning the Generation of Living Creatures. London.

Hues, Robert. 1639. A Learned Treatise of Globes. London.

Jameson, Fredric. 1988. "Of Islands and Trenches: Neutralization and the Production of Utopian Discourse." In The Ideologies of Theory: Essays 19711986. 2 vols. 2:75-101. Minneapolis.

Kaufmann, Thomas DaCosta. 1993. The Mastery of Nature: Aspects of art, science, and humanism in the Renaissance. Princeton.

Kegl, Rosemary. 1996. "Margaret Cavendish, feminism, and The Blazing World." In Feminist Readings of Early Modern Culture, ed. Valerie Traub, M. Lindsay Kaplan, and Dympna Callaghan, 119-41. Cambridge.

Keller, Eve. 1997. "Producing Petty Gods: Margaret Cavendish's Critique of Experimental Science." ELH 64: 447-71.

Kahn, Victoria. 1997. "Margaret Cavendish and the Romance of Contract." Renaissance Quarterly 50: 526-66.

Lagalla, Julius Caesar. 1612. De phaenomenis in orbe lunae novi telescopii. Venice.

Marin, Louis. 1984. Utopics: Spatial Play. Trans. Robert A. Volrath. Atlantic Highlands.

Mintz, Samuel. 1952. "The Duchess of Newcastle's Visit to the Royal Society." JEGP 51: 168-76.

Moss, Jean Dietz. 1993. Novelties in the Heavens: Rhetoric and Science in the Copernican Controversy. Chicago.

Nicolson, Marjorie. 1935. "Milton and the Telescope." ELH 2: 1-32.

-1956. Science and Imagination. Ithaca.

Panofsky, Erwin. 1954. Galileo as a Critic of the Arts. The Hague.
Petruci, Armando. 1993. Public Lettering; Script, Power, and Culture. Trans. Linda Lappin. Chicago.

Rash-Fabbri, Nancy. 1979. "A Note on the Stanza Della Segnatura." Gazette des Beaux-Arts 94: 97-104.

Reeves, Eileen. 1997. Painting the Heavens: Art and Science in the Age of Galileo. Princeton.

Reiss, Timothy J. 1977. "Espaces de la Pensée Discursive: Le Cas Galilée et la Science Classique." Révue de Synthèse 85-86: 5-47.

1982. The Discourse of Modernism. Ithaca, 1982.

1997. Knowledge, Discovery, and Imagination in Early Modern Europe: The Rise of Aesthetic Rationalism. Cambridge.

Rogers, John. 1996. The Matter of Revolution: Science, Poetry, and Politics in the Age of Milton. Ithaca.

Rorty, Richard. 1979. Philosophy and the Mirror of Nature. Princeton.

Rosen, Edward. 1947. The Naming of the Telescope. New York.

Sarasohn, Lisa T. 1984. "A Science Turned Upside: Feminism and the Natural Philosophy of Margaret Cavendish." Huntington Library Quarterly 47: 289307.

Shapin, Steven. 1988. "The House of Experiment in Seventeenth-Century England." Isis 79: 373-404.

Shapin, Steven and Simon Schaffer. 1985. The Leviathan and the Air-Pump: Hobbes, Boyle, and the Experimental Life. Princeton.

Shapiro, Barbara J. 1983. Probability and Certainty in Seventeenth-Century England: A study of the relationships between natural science, religion, history, law, and literature. Princeton.

Sherman, Sandra. 1994. "Trembling Texts: Margaret Cavendish and the Dialectic of Authorship." English Literary Renaissance 24: 184-210. 
Sidney, Sir Philip. 1985, reprint. An Apology for Poetry. Ed. Forrest G. Robinson. 1972. New York.

Spiller, Elizabeth A. 1999. "Sighting Utopia in the Lens: Reading Praxis in Johannes Kepler and Margarer Cavendish." Journal x 3.2: 147-69.

Stevens, Henry. 1900. Thomas Hariot. London.

Stevenson, Jay. 1996. "The Mechanist-Vitalist Soul of Margaret Cavendish." SEL 36: 527-43.

Wilkins, John. 1638. The discovery of a world in the moone. London.

Winkler, Mary G. and Albert Van Helden. 1992. "Representing the Heavens: Galileo and Visual Astronomy." Isis 82: 195-217.

1993. "Johannes Hevelius and the visual language of astronomy." In $R e$ naissance and Revolution: Humanists,
Scholars, Craftsmen, and Natural Philosophers in Early Modern Europe, ed. J. V. Field and Frank A. J. L. James, 96116. Cambridge.

Valcanover, Francesco and Terisio Pignatti. 1985. Tintoretto. Trans. Robert Erich Wolf. 3 vols. New York.

Van Helden, Albert. 1976. "The 'Astronomical Telescope,' 1611-1650." Annali del' Istituto e Museo di Storia della Scienza di Firenze 1.2: 13-36. , ed. and trans. 1989. Sidereus nuncius or the Sidereal Messenger; Galileo Galilei. Chicago.

1994. "Telescopes and Authority from Galileo to Cassini." Osiris 9: 929.

Vespucci, Amerigo. 1916. Mundus Novus. Trans. George Tyler Northrup. Princeton. 